\title{
Evaluation of wind park tax incentives in Colombia by means of real options
}

\author{
Miguel Jiménez-Gómez ${ }^{1}$, Natalia Acevedo-Prins² \\ ${ }^{1,2}$ Facultad de Ciencias Económicas y Administrativas, Instituto Tecnológico Metropolitano-ITM, Colombia \\ ${ }^{1}$ Facultad de Minas, Universidad Nacional de Colombia, Colombia
}

\begin{tabular}{l} 
Article Info \\
\hline Article history: \\
Received Dec 2, 2019 \\
Revised Jan 24, 2020 \\
Accepted Feb 4, 2020 \\
\hline
\end{tabular}

Keywords:

Energy price

Real options

Renewable energy

Wind farm

\begin{abstract}
The objective of this study is to assess tax incentives in Colombia to foster investment in wind parks. Fiscal incentives seek to diversify energy consumption with non-conventional renewable energy sources, since power is mostly generated by hydraulic force and since its price is impacted during dry seasons. The price of energy is modeled according to a regression toward the mean. This stochastic process was chosen because during droughts in Colombia there are price increases, which then return to their average value. This is an upward and downward spike behavior, as well as a regression toward the mean. Given price uncertainty and its impact on cashflow, wind parks were valued with real options to flatten the reversal for five years. The real option of flattening as an American call option was considered. Results show that, according to traditional valuation methods, wind parks in Colombia are not profitable even with tax incentives. However, according to the real options method, tax incentives do make these projects economically viable.
\end{abstract}

Copyright $(0) 2020$ Institute of Advanced Engineering and Science. All rights reserved.

\section{Corresponding Author:}

Miguel Jiménez-Gómez,

Instituto Tecnológico Metropolitano-ITM,

Universidad Nacional de Colombia,

Calle 54 A \#30-01, Medellín, Colombia.

Email: luisjimenez@itm.edu.co

\section{INTRODUCTION}

Energy in Colombia is mostly generated by renewable sources, specially hydraulic power $(80 \%)$. Therefore, energetic supply depends on the country's climatic conditions. Given its geographical location, Colombia has seasons of abundant floods, called La Niña, as well as droughts with high winds, a phenomenon called El Niño. Both periods affect energy production in Colombia, yet El Niño has a more significant negative impact, since it threatens with power rationing and prices escalate [1]. During the droughts, dams are emptied and wind increases. Energy obtained from wind power represents only $0.14 \%$ approximately in a single wind park located a La Guajira, a region characterized for being windy all year round.

Wind parks represent a complement to diversify energy sources. However, the high costs of these technologies prevent their development in Colombia. Traditional project valuation methods, such as Net Present Value (NPV) and Internal Return Rate (IRR), indicate that current market conditions do not favor investment. Yet, these valuation methods do not consider the strategic dimension of investments in renewable energy projects, given the risk and uncertainty associated with future rewards [2]. Traditional methods do not consider other dimensions of energy projects when they are highly uncertain and volatile [3]. Therefore, more sophisticated valuation techniques are needed to solve this, such as the Real Options theory, which considers the project as an investor with financial options. This method provides flexibility to exercise the option while waiting for the technological or market conditions to change [2]. 
Random models based on a geometric Brownian motion (GBM) are commonly used in the Real Options method, considering a Wiener process which assumes that each price is independent from another. However, it also considers that the historic price route is irrelevant to predict future cost behavior, which is unrealistic in the case of energy production [4]. A GBM assumes that investment yields in a project follows a log-normal distribution. Nevertheless, this is not true for energy projects, where price performance shows mean reversion, leaps and peaks [5]. The quickest solution to this problem is the use of a stochastic process that captures mean reversion and peaks in energy prices, which is the most uncertain variable in these projects. Energy price prediction plays an important role in sector investment and expansion.

This paper's contribution lies in the modeling of energy prices with its mean reversion and peaks, since some previous studies include the mean reversal, yet disregard price increases. The second contribution is the valuation of the wind park according to Real Options, analyzing the effect that the energy policy in Colombia has which encourages investment in energy generation projects from unconventional sources, as made by way of law 1715 of 2014 in Colombia.

The academic growth of literature on real options in renewable energy shows the increasing interest in this subject. Ten articles reviewing the application of real options in renewable energy projects were found on the Scopus database [2, 6-14]. These studies consider energy prices uncertain variables of great relevance in renewable energy projects. Most studies modeled energy prices with a GBM, while just a few applied a mean reversion. It is common to find price subsidies in energy generation projects. Studies in Asia have established the Feed-in-Tariff (FiT) as an incentive measure for these projects. FiT guarantees a minimum energy sales price for some renewable energy projects, generally those where production is most costly, such as wind and solar technology. Some articles report the sale of CO2 as an additional entry into energy generation projects, which is modeled in the GBM. Lastly, the following facts regarding the application of Real Options in renewable energy are found: this method increases the value of wind projects in most scenarios [15]; it is highly effective when quantifying uncertainty in the planning of inversion in the development of renewable energy projects [16]; and it is economically more attractive when responding to the uncertainty of the energy market [17].

Dixit \& Pindyck, Trigeorgis \& Amram, and Kulatilaka made the most important contributions to the theory of real options. Subsequently, this theory was applied to investment in different sectors, including the energy sector. Most common applications of Real Options in the literature fall into three main categories:

a) Analytical methods that quantify a project's flexibility;

b) Mallet methods such as binomial trees taken directly from extended finances to real assets;

c) The Monte Carlo method.

Kozlova [9] conducted a literature review on the valuation of renewable energy through Real Options where all 100 papers analyzed used one of these three categories and applied stochastic processes such as GBM and mean reversion to model uncertain variables, specially for energy prices. Gazheli \& Bergh [2] also found this in the literature review on wind and solar energy inversions by means of real options.

\section{RESEARCH METHOD}

This paper applies Real Options for the deferral of a wind park in Colombia. Data on the only wind park in Colombia, called Jepírachi, with a capacity of $19.5 \mathrm{MW}$, was used. The amount of energy produced in this project in a year was obtained. The operating and maintenance costs and the current initial investment of these projects according to IRENA (International Renewable Energy Agency) were used Table 1. Cash flow projection for the wind park was estimated for 25 years with these data. The uncertain variable modeled was energy price. The real option of flattening the project is valued by the binomial tree method with a five-year maturity. Real Options valuation was made excluding tax incentives, but including law 1715 of 2014 incentives.

Table 1. Data for cash flow projection

\begin{tabular}{cc}
\hline Variable & Worth \\
\hline Operation and maintenance fixed costs & $70 \mathrm{USD} / \mathrm{MWh}$ \\
Nominal capacity & $19.5 \mathrm{MW}$ \\
Investment cost & $1,477,000 \mathrm{USD} / \mathrm{MW}$ \\
Production & $72,000 \mathrm{MWh} /$ year \\
CO2 tons & $15,277.35 \mathrm{tCO} 2 /$ year \\
\hline Source: $[18,19]$ &
\end{tabular}




\subsection{Real option valuation on deferral}

Real Options was a term coined by Myers in 1977, referring to options in investment opportunities as deferral, expanding, exchanging, suspending or abandoning a project. Generally, Real options are not part of a buy and sell market. A real option asset does not trade in a market and is subject to strategic interactions with its surroundings. Each real option is unique depending on its context and requires a personalized assessment [20].

A company or project's investment opportunities are quantified in real options and are calculated with methods of financial option valuation. This is the quantification of flexibility, so the project's NPV by real options consists of two components: (a) traditional static NPV, and (b) flexibility, which captures real option values. To quantify flexibility, traditional models are used, such as the Black-Scholes analytical method, a discrete equation that includes binomial, trinomial trees, and the Monte Carlo simulation. However, like real options, they are mainly American because decisions can be made at any time until the investment opportunity disappears. Therefore, the discrete valuation model is applied more frequently [21].

The real option for investment deferral is the decision to wait for better conditions to implement a project. It is similar to a call option on the present value of a project's expected cash flow. In the deferral real option, the anticipated realization of the project is compared with the value of not carrying it out, while waiting on market conditions that favor investment [6]. This real option is of the American type, where the decision is evaluated at every moment in time. Therefore, assessment should be performed by the binomial tree method that is appropriate for American options.

The binomial tree method consists in estimating the price of an underlying asset over a period of time, and the financial option can be exercised at any time during a given period. This method considers short time intervals to evaluate the price value, which could be considered as fluctuating in only two ways: (a) $u$ percentage increases $(u>1)$, or $(b) d$ percentage decreases $(d<1)$. In the binomial tree of a single step Figure 1, the current price of the underlying asset is $S 0$, and the price at the time of maturity may be $S_{u}$ o $S_{d}$, where $S_{u}=S_{0} * u$ and $S_{d}=S_{0} * d$. The price of the call option at the time of expiration is calculated as $f_{u}=S_{0}-K$ if $S_{u}>K$, or $f_{u}=0$ if $S_{u}<K, f_{d}=S_{d}-K$ if $S_{d}>K$, or $f_{d}=0$ if $S_{d}<K$ [22]. The letter $K$ denotes the strike price of the option. The price of the financial option (f) is calculated with the probability of the underlying asset's price rises (p) and option values at expiration (1).

$$
f=\left[p f_{u}+(1-p) f_{d}\right] e^{-r T}
$$

Where $p=\frac{e^{r T}-d}{u-d}, u=e^{\sigma \sqrt{T}}, d=\frac{1}{u}, \mathrm{r}$ is risk-free rate effective until the expiration of the financial option and $\sigma$ is the volatility of the underlying asset.

Investment projects can be considered with many time intervals, where each time interval is a step in the binomial tree. A binomial tree of $\mathrm{N}$ steps can be used as shown in Figure 2. The call option value on each fi,j node is calculated with $f_{i j}=\max \left(S_{i j}-K, 0\right)$, where $S_{i j}$ corresponds to the value of the underlying asset in the node $(i, j)$, with $i=1,2, \ldots, n ; j=1,2, \ldots, i$. Each time the fi, price is estimated, the option price in the previous node is calculated in (2) [22].

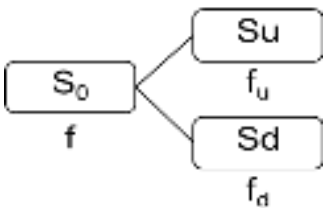

Figure 1. Single-step binomial tree for the underlying asset and the financial option

$$
f_{i-1, j-1}=\left[p f_{i, j}+(1-p) f_{i, j-1}\right] e^{-r \Delta T}
$$

Where $\Delta T=\frac{T}{n}$ is the duration of time in each step.

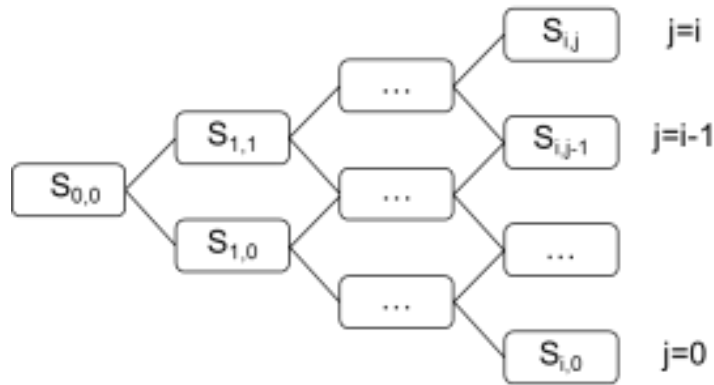

Figure 2. N-step binomial tree of the underlying asset and the financial option 
The binomial tree method for the deferral real option is used with the same procedure and only the variables for the real project are changed, where: $S_{0}$ is the present value of the project's cash flow projection, $\mathrm{K}$ is the investment cost at the moment the decision to invest is made, $\sigma$ is the volatility of cash flow present value, and $\mathrm{r}$ is the discount rate. A Monte Carlo simulation should be carried out with cash flow projection to estimate project volatility, where uncertain variables that can be modeled should be considered. In this case, the uncertain variable of the wind park is energy prices. Variable modeling is described below.

\subsection{Colombia energy price modeling}

Energy prices in Colombia are characterized by mean reversion with peaks. The geographic location of Colombia makes the country's climatic conditions affect power generation, because it regularly uses hydraulic sources. During El Niño, a period characterized by drought and strong winds, the price of energy increases. Later, the price decreases and returns to more frequent ones. Figure 3 shows the behavior of energy prices in Colombia from 2008 to the first months of 2019.

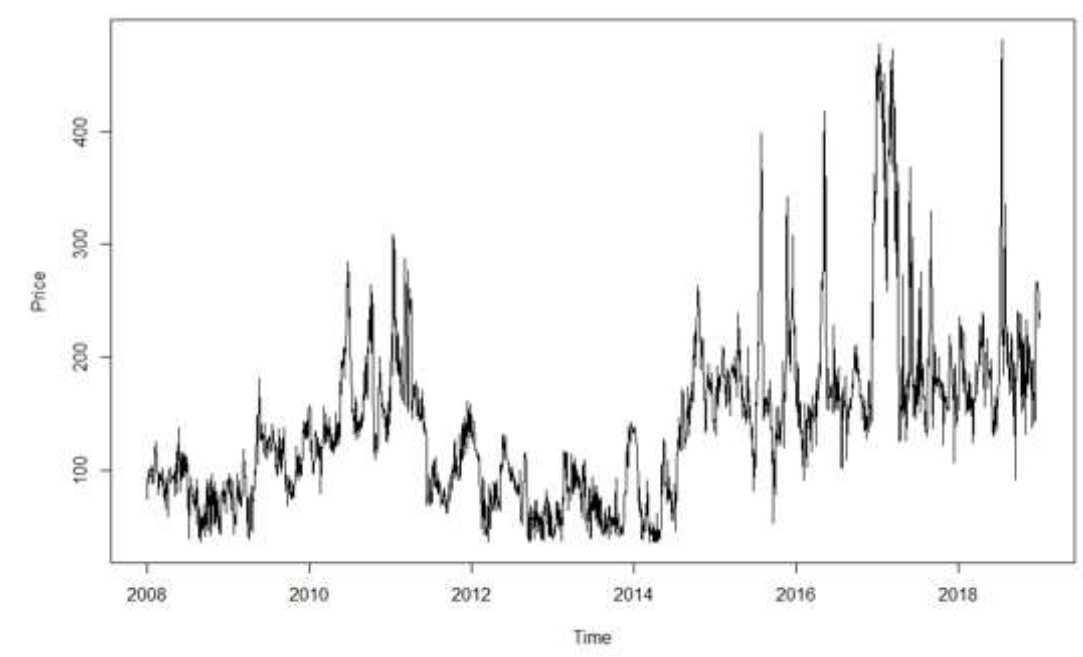

Figure 3. Energy price behavior

The process of mean reversion with peaks is shown in (3).

$$
d S=\eta(\bar{x}-x) d t+\sigma d z+d q
$$

Where $\eta$ represents the rate of mean reversion of the asset, $\mathrm{dt}$ is the time interval, $\sigma$ is the asset's expected volatility, $\mathrm{dz}$ is a Wiener process with normal distribution of zero mean and variance one, and dq is a Poisson term that has a value of zero most of the time, but often $\lambda$ assumes a value that causes peak pricing. In this stochastic process, $\mathrm{dz}$ and $\mathrm{dq}$ are not correlated [23].

Peak pricing occurs with a $\lambda_{\mathrm{u}}$ frequency and troughs, with a $\lambda_{\mathrm{d}}$ frequency. In this way, $\lambda$ is equal to the sum of $\lambda_{\mathrm{u}}$ and $\lambda_{\mathrm{d}}$. Peak size and direction are random and the hope of the joint distribution $\varphi$ of peaks and troughs is $k=E[\varphi]$, where $\varphi_{\mathrm{u}}$ is peak distribution and $\varphi_{\mathrm{d}}$, trough distribution [23] (4).

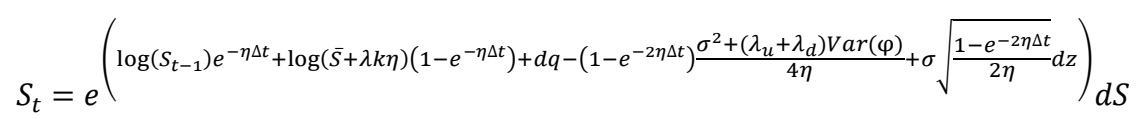

Where St corresponds to the price modeled in the time interval $\mathrm{t}$ and $\bar{S}$ represents the asset's average expected value. Data in Table 2 on energy prices in Colombia serve to model the variable with a mean reversion process with peaks.

Figure 4 shows an example of the Monte Carlo simulation with 20 scenarios per unit of time of a mean reversion process with peaks on energy prices. The gray horizontal line corresponds to the last known real price, and the black horizontal line corresponds to the mean reversal value. Price trajectories tend to fall; given the mean reversal value is lower than the last known price, as well as there up and down trends. This behavior is similar to that of energy prices in Colombia Figure 3. 
Table 2. Energy price data to model mean

\begin{tabular}{|c|c|}
\hline Variable & Worth \\
\hline $\mathrm{S}_{0}$ & $\$ 309.06$ \\
\hline $\bar{S}$ & $\$ 111.33$ \\
\hline$\sigma$ & $12.04 \%$ \\
\hline$\lambda_{\mathrm{u}}$ & 0.00997 \\
\hline$\lambda_{\mathrm{d}}$ & 0.00860 \\
\hline$E\left[\varphi_{u}\right]$ & 0.10287 \\
\hline$E\left[\varphi_{d}\right]$ & -0.10371 \\
\hline $\operatorname{Var}[\varphi]$ & $2.134 \%$ \\
\hline $\mathrm{dt}$ & 365 \\
\hline
\end{tabular}

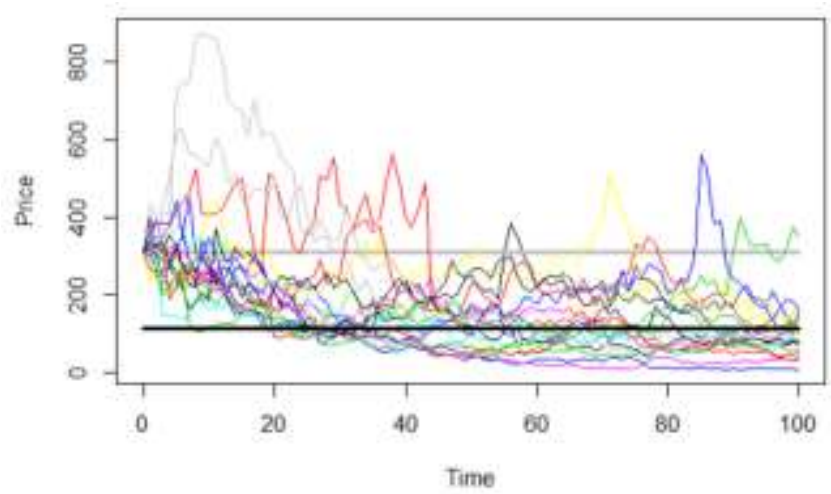

Figure 4. Mean reversion process with peaks in energy price

\subsection{Wind park cash flow}

Project cash flow is shown in (5). Operating income from energy sales, operating costs based on power generation, and income taxes of $33 \%$ without exemptions are considered. Tax is paid only if there is a positive cash flow before taxes. Asset depreciation is done in a straight line for 25 years.

$$
\begin{gathered}
\text { Cash flow }=(\text { operating income }- \text { operating costs } \times \text { power generation } \\
- \text { depreciation }) \times(1-33 \%)+\text { depreciation }
\end{gathered}
$$

Articles 11 and 14 of Law 1715 of 2014 grant tax incentives to renewable energy generation projects from unconventional sources: (a) five-year annual reduction of 50\% of the total investment, and (b) asset accelerated depreciation with an annual rate of $20 \%$. These two incentives change project cash flow, causing increases when less taxes are paid, or even when no taxes are paid at all

\section{RESULTS AND ANALYSIS}

The 25-year cash flow projection of a wind park in the Colombian market was carried out with data on the annual energy generation in Jepírachi. Two scenarios were considered: one without incentives, and another with incentives according to the energy policy presented in Law 1715 of 2014. Once estimation was obtained, the uncertain variable in the project was modeled in order to assess the real option to defer.

According to cash flow projection and simulation, the project's NPV without incentives was US\$9,370,162, while the scenario with incentives was US\$2,675,485. While the difference shows that Law 1715 of 2014 can potentially promote investment in wind parks, the impact is not sufficient, since NPV remains negative, and so investors continue to reject the project. However, these projects are characterized by high volatility and uncertainty, and by the options that management can take over time and that NPV is unable to quantify. Therefore, the Real Options method is applied with the option of postponing the decision to invest in the wind park for up to five years.

After the simulation of energy prices in project cash flow was ran, the volatility for the scenario without incentives resulted in $43.74 \%$, while it resulted in $40.53 \%$ with incentives. This means fiscal enticements regarding energy policy help achieve better cash flows for the investor and reduce volatility risks. Input variables for the assessment of the deferral real option are shown in Table 3.

Table 3. Variables to assess real option for energy projects without incentive

\begin{tabular}{ccc}
\hline Variable & Notation & Value \\
\hline Present value expected cash flows & S0 & $19,431,338$ USD \\
Initial investment & $\mathrm{K}$ & $28,801,500$ USD \\
Cash flow volatility & $\sigma$ & $43.74 \%$ \\
Discount rate & $\mathrm{r}$ & $9.54 \%$ annual \\
Deadline to assess deferral & $\mathrm{T}$ & 5 years \\
\hline
\end{tabular}

After applying the real options method, the decision tree for deferral is obtained. Figure 5 shows the binomial decision tree for the scenario without incentives. According to this valuation method, the project is not initially rejected, rather, it is postponed until market conditions favor it. Thus, Figure 5 shows the 
project is postponed for a year with a favorable scenario to invest; favorable conditions are also obtained for the second year; in year three, two scenarios; in the fourth year, two scenarios; and in year five, three scenarios.

Results in the decision tree are the same for the scenario with fiscal incentives Figure 6. These scenarios differ in the value of the actual defer option. The option to defer has a value of $\$ 7,429,563$ without considering incentives, while in the scenario with incentives the value is $\$ 12,562,627$. Investment deferral for up to five years indicates that, in any scenario, the project should not be rejected and could be postponed until favorable conditions are obtained, which are expected since the first year.

Better results are obtained by including the real option value in the NPV. Without tax benefits, the new NPV including the real option is US\$1,940,598. With tax benefits, the new NPV is US\$9,887,143. The quantification of the flexibility to postpone shows that it is possible to accept the energy project as long as the benefits of Law 1715 of 2014 are applied. However, if the real option does not include these benefits, the project is rejected, given NPV remain negative.

Deferral represents $38 \%$ of the present value of the project cash flow without incentives, and $48 \%$ in the scenario with incentives. The real option to defer manages to increase the project's NPV without incentives by $79 \%$, and $470 \%$ in the project with incentives. Drastic changes in project value are obtained with the Real Options method, however, the literature states that these energy projects are highly volatile and uncertain, and these high values are reached due to volatility and differences between $S_{0}$ and $K$.

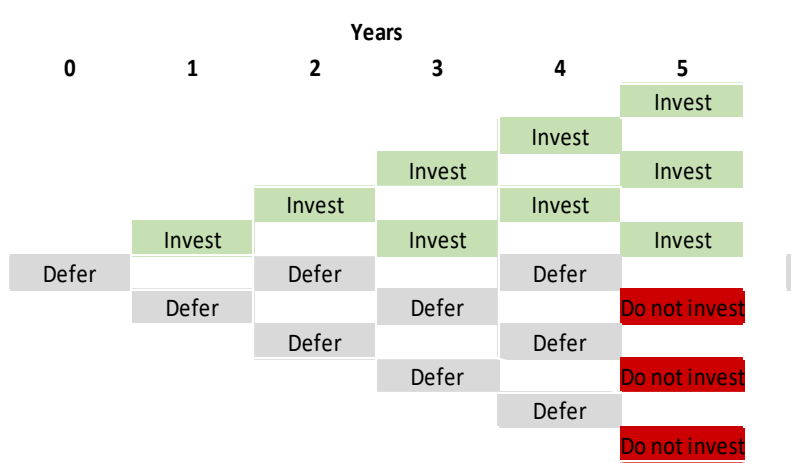

Figure 5. Binomial decision tree for the scenario without incentives

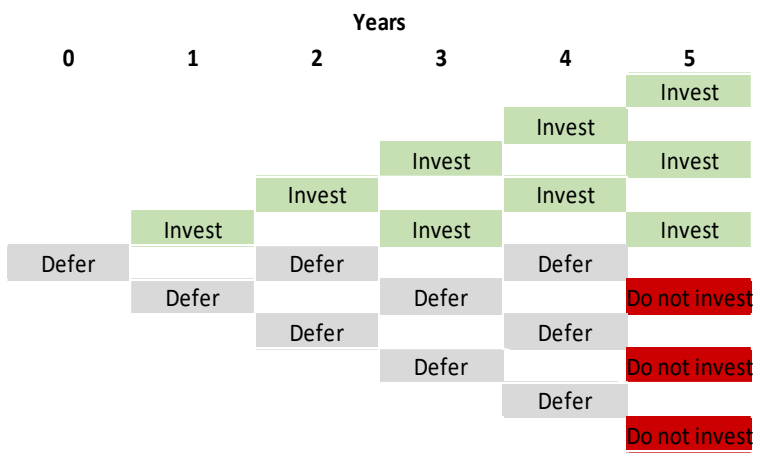

Figure 6. Binomial decision tree for the scenario with incentives

\section{CONCLUSION}

Project management can analyze market conditions through the application of Real Options, as information is obtained and uncertainty is reduced. Energy generation projects are highly uncertain because of the variability in energy prices, and even more so those that work with non-conventional renewable sources. The latter are usually not viable due to investment costs. Non-conventional source generation projects are not economically viable if they are considered under traditional project valuation methods, such as the NVP. However, these methods are not capable of quantifying managerial flexibility such as deferring the project until market conditions favor investment. The Real Options method quantifies this managerial flexibility through the valuation used in financial options. The value of managerial flexibility measured by with Real Options has a higher NPV proportion, which makes projects with tax incentives more attractive to investors; rather, it is not enough without incentives as the project continues to be financially rejected.

None of the evaluation methods are considered absolute. Regardless, there is need to search for alternative evaluation methods that contemplate uncertainty and flexibility in management as investment characteristics. Although Real Options is a difficult and uncommon method for companies, it is the most recent and appropriate to apply to uncertain issues. Therefore, if an analysis takes into account uncertainty over time and includes real options in the project, the decision-making process will be more realistic.

Literature review shows that, due to high levels of uncertainty, investment in energy projects are assessed. Yet, investment decisions should not be limited to now or never. In fact, a certain degree of flexibility in management must be included. Most studies that apply Real Options to energy generation projects from renewable sources consider prices as the variable of greatest uncertainty, and model it based on Geometric Brownian Movement, or with a process of mean reversion. The application is novel in this paper because a mean reversion process with peaks was applied, using this method of modeling the price of energy and the valuation by real options. 


\section{REFERENCES}

[1] J. Contreras and Y. E. Rodríguez, "Incentives for wind power investment in Colombia," Renew. Energy, vol. 87, pp. 279-288, 2016.

[2] A. Gazheli, and J. Van Den Bergh, "Real options analysis of investment in solar vs. wind energy: Diversification strategies under uncertain prices and costs," Renew. Sustain. Energy Rev., vol. 82, pp. 2693-2704, 2018.

[3] S. Awerbuch and M. Berger, "Applying portfolio theory to E.U. electricity planning and policy-making," vol. 3, 2003.

[4] J. Pless, et al, "Quantifying the value of investing in distributed natural gas and renewable electricity systems as complements: Applications of discounted cash flow and real options analysis with stochastic inputs," Energy Policy, vol. 97, pp. 378-390, 2016.

[5] J. A. Schachter, and P. Mancarella, "A critical review of Real Options thinking for valuing investment fl exibility in Smart Grids and low carbon energy systems," Renew. Sustain. Energy Rev., vol. 56, pp. 261-271, 2016.

[6] B. Fernandes, J. Cunha, and P. Ferreira, "The use of real options approach in energy sector investments," Renew. Sustain. Energy Rev., vol. 15, no. 9, pp. 4491-4497, 2011.

[7] A. Ioannou, A. Angus, and F. Brennan, "Risk-based methods for sustainable energy system planning: A review," Renew. Sustain. Energy Rev., vol. 74, pp. 602-615, 2017.

[8] K. Kim, H. Park, and H. Kim, "Real options analysis for renewable energy investment decisions in developing countries,” Renew. Sustain. Energy Rev., vol. 75, pp. 918-926, 2016.

[9] M. Kozlova, "Real option valuation in renewable energy literature: Research focus, trends and design," Renew. Sustain. Energy Rev., vol. 80, pp. 180-196, 2017.

[10] D. Loncar, et al., "Compound real options valuation of renewable energy projects : The case of a wind farm in Serbia," Renew. Sustain. Energy Rev., vol. 75, pp. 354-367, 2017.

[11] E. A. Martínez Ceseña, J. Mutale, and F. Rivas-Dávalos, "Real options theory applied to electricity generation projects: A review,” Renew. Sustain. Energy Rev., vol. 19, pp. 573-581, 2013.

[12] M. Zhang, D. Zhou, and P. Zhou, “A real option model for renewable energy policy evaluation with application to solar PV power generation in China," Renew. Sustain. Energy Rev., vol. 40, pp. 944-955, 2014.

[13] M. M. Zhang, et al., "Optimal design of subsidy to stimulate renewable energy investments : The case of China," Renew. Sustain. Energy Rev., vol. 71, pp. 873-883, 2017.

[14] A. Menegaki, "Valuation for renewable energy: A comparative review," Renew. Sustain. Energy Rev., vol. 12, no. 9, pp. 2422-2437, 2008.

[15] E. A. Martinez-Cesena, and J. Mutale, "Wind power projects planning considering real options for the wind resource assessment," Sustain. Energy, IEEE Trans., vol. 3, no. 1, pp. 158-166, 2012.

[16] S.-C. Lee, "Using real option analysis for highly uncertain technology investments: The case of wind energy technology," Renew. Sustain. Energy Rev., vol. 15, no. 9, pp. 4443-4450, 2011.

[17] K. T. Kim, D. J. Lee, and S. J. Park, "Evaluation of R\&D investments in wind power in Korea using real option," Renew. Sustain. Energy Rev., vol. 40, pp. 335-347, 2014.

[18] A. Pinilla, L. Rodriguez, and R. Trujillo, "Performance evaluation of Jepirachi Wind Park," Renew. Energy, vol. 34, no. 1, pp. 48-52, 2009.

[19] IRENA, "Wind power," 2019. [Online]. Available: https://www.irena.org/costs/Power-Generation-Costs/WindPower.

[20] B. M. Lambrecht, "Real options in finance,” J. Bank. Financ., vol. 81, no. 2017, pp. 166-171, 2017.

[21] M. Čulík, "Real options valuation with changing volatility," Perspect. Sci., vol. 7, pp. 10-18, 2016.

[22] K. Guo, L. Zhang, and T. Wang, "Optimal scheme in energy performance contracting under uncertainty: A real option perspective," J. Clean. Prod., vol. 231, pp. 240-253, 2019.

[23] J. Mascareñas, et al., "Opciones reales y valoración de activos," Madrid: Prentice Hall, 2004. 